\title{
Built to Code Building Envelop Versus Sustainability of High-Rise Building Performance
}

\author{
Mohamed ali karim* \\ Department of Civil Engineering, College of Engineering, Elmergib University, Libya \\ DOI: https://doi.org/10.21467/proceedings.4.3 \\ * Corresponding author email: omgaon2x@yahoo.com
}

\begin{abstract}
Global warming and climate change are major challenges facing the nation and the world. More than two thirds of the electric energy and one third of the total energy are used to heat, cool, and operate buildings, representing majority of all CO2 emissions. A reduction in building energy consumption will help to mitigate the energy security and climate change effects on buildings. The reduction in energy consumption is accomplished through the development of new technologies (for the building's envelope, mechanical, and lighting systems) that save energy and reduce CO2 emissions. However, an alternative approach is the use of passive systems that employ renewable energy sources. Passive systems avoid the need for heating or cooling through better design, construction, and operation. They utilize solar or wind energy to heat, cool, or light buildings. This study analyzes the sensitivity of energy demanded to build to code building's envelops. In other words, investigating whether building that meets the need of enveloping code can take advantage of the weather surrounding the building, in terms of cooling, or heating (comfort) the building as needed. Four high-rise office buildings (glazed curtain wall) with four different aspect ratios (1:1, 1:2, 1:3, and 1:4) are thermally analyzed in four climate zones: cool, temperate, arid, and tropical. The envelope of these high-rise buildings is modeled to meet International Energy Conservation Code (IECC) requirements, which references several American Society of Heating, Refrigeration, and Air Conditioning Engineers (ASHRAE) standards. As a result, the energy performance of high-rise office buildings is not sensitive to the passive solar gain as long as the exterior envelopes are built to IECC 2009 requirements, which does not allow the use of the ambient climate condition of the building to get comfort. This is not appropriate from the concept of sustainability of buildings as referred to above.
\end{abstract}

Keywords: Sustainability, High-Rise Building, Energy performance, Global warming

\section{Introduction}

One of the criteria for the development of countries is the urban renewal, especially the highrise buildings in their cities. Thousands of years, tall buildings and towers have fascinated human beings; they have been built primarily for defensive or religious purposes as evidenced by the Pharaonic temples (pyramids) of Giza, Egypt, the Mayan temples of Tikal, Guatemala, and the Kutub Minar of Delhi, India. In the modern era, high-rise buildings are a reality of

(C) 2018 Copyright held by the author(s). Published by AIJR Publisher in Proceedings of First Conference for Engineering Sciences and Technology (CEST-2018), September 25-27, 2018, vol. 2.

This is an open access article under Creative Commons Attribution-NonCommercial 4.0 International (CC BY-NC 4.0) license, which permits any non-commercial use, distribution, adaptation, and reproduction in any medium, as long as the original work is properly cited. ISBN: 978-81-936820-6-7 
contemporary life in cities and there are several reasons for this. Urban real estate is a premium due to the lack of available land; secondly, high-rise buildings (vertical construction) present an effective way to reduce traffic congestion in cities; thirdly, rapid population growth of urban communities, lastly, the limitations and the conditions of the terrain and topography $[1,2]$. However meeting operational performance requirements and maintaining occupant comfort in high-rise buildings is a challenging design problem. The energy demands for large-scale HVAC system (Heating, Ventilating, and Air Conditioning) load is significant. Not only are the site energy costs are high, the attendant environmental consequences of using nonrenewable energy sources are great. Improving the energy efficiency of high-rise buildings is a key component in increasing the sustainability of the environment. More than one-third of the world's energy consumption is attributed to the construction and building industry [3]. As a case, more than two thirds of the electric energy and one third of the total energy in the US are used to heat, cool, and operate buildings [4], representing roughly $18 \%$ of all U.S. CO2 emissions in one year. Given the current global energy crisis, there is a critical need to design and construct buildings that are more sustainable. Energy efficient buildings minimize building resource consumption, operations and life cycle costs, and can improve occupant health and comfort [5]. High-rise buildings should be designed in a manner to reduce the need for fossil fuels (oil, gas and coal) and promote greater reliance on renewable energy. This concept is reflected in what is known these days as sustainable architecture or green building. A green building is one that focuses on reducing the impact of buildings on the environment. In general, a green building is one that meets the needs of the present generation without compromising the ability of future generations to meet their needs as well [1]. For designers and architects such as William Reed, green buildings are designed, implemented, and managed in a manner that places the environment first[6]. In the state of Libya, the architectural renaissance will be an urgent necessity for the follow-up to the developed nations in this world; as the state of Libya adopts building specifications, which may not be compatible with the requirements of sustainability in terms of temperate climate. Moreover, the current standards of architectural systems do not adopt fully sustainable methods, since the concept of sustainability is a newborn concept and its implementation is economically expensive because of the cost of the techniques used. States are in a race to lay the foundations for sustainable construction. In keeping with the demand for the current architectural development, nations cannot wait for complete and integrated system to be built in sustainable ways. Thus, the idea of this research is to study if these specifications meet the requirements of sustainably performance of high building that are built according to these codes and standards (IECC code and ASHRAE standards) of the buildings envelope [7]. The study analyzes the sensitivity of energy demanded to build to code buildings envelopes. In other words, investigating whether a building that meets the need of envelop code can take advantage of the weather surrounding the building, in terms of cooling, or heating (comfort) the building as needed.

Proceedings of First Conference for Engineering Sciences and Technology (CEST-2018), vol. 2 
Built to Code Building Envelop Versus Sustainability of High-Rise Building Performance

Four high-rise office buildings (glazed curtain wall) with four different aspect ratios (1:1, 1:2, 1:3, and 1:4) are thermally analyzed in four climate zones: cool, temperate, arid, and tropical. Energy demand is calculated for each model with respect to two opposing orientations (Figure1). The four high-rise buildings are modeled to meet IECC 2009 code requirements, which reference several ASHRAE standards, including Std. 90.1 for commercial building construction [7, 8]. The following sections describe the analytical method and the primary variables that will be measured against energy use in the four-modeled buildings. Then summarize the results and present the conclusion.

\section{Building Materials and Basic Data}

Four models of high-rise office buildings are considered in this study to evaluate the sensitivity of energy demands to variations in: (1) footprint aspect ratio (1:1, 1:2, 1:3, and 1:4), and (2) building orientation. Since the goal is to isolate the influence of built to code building's on energy demand, all other buildings descriptors such as the square footage, number of stories, building height(Figure 2), and occupancy for the four buildings are held constant across all four buildings. Specifically, the thermostat range, internal design conditions, occupancy, infiltration rate, and hours of operation as fixed control variables.
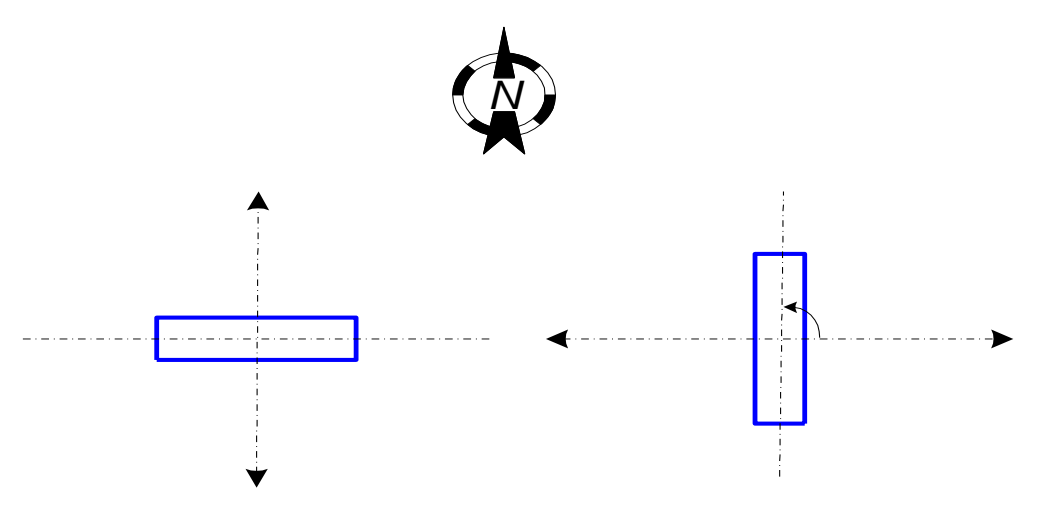

Figure.1. Building orientation considered in this study

The four buildings are 200 meters in height, 50 stories that are $4.0 \mathrm{~m}$ floor-to-floor height, with a total conditioned floor area of 135,000 square meters. The primary material for the meet the R-value specified for a climate according IECC 2009. To simplify the thermal analysis, the effect of surrounding buildings have been neglected assuming that the buildings were erected on flat open ground and are aligned with the cardinal directions. 


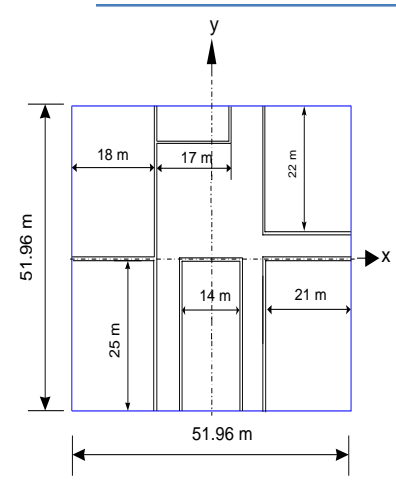

Plan view 1:1 configuration

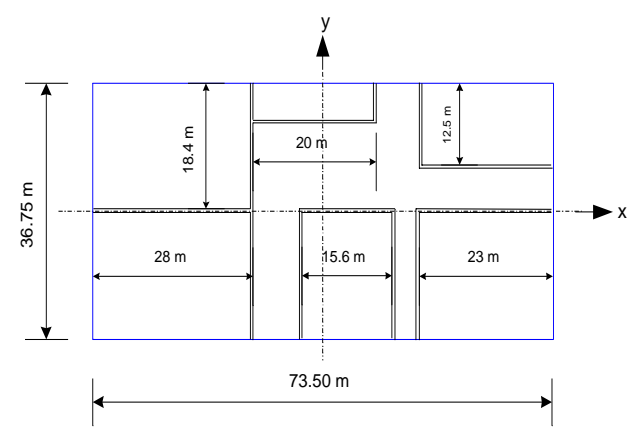

Plan view 1:2 configuration

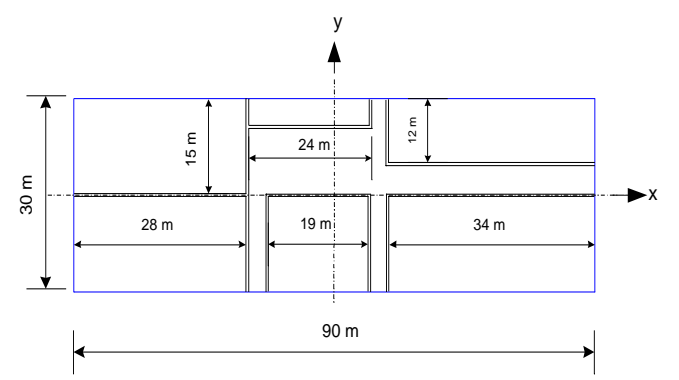

Plan view 1:3 configuration

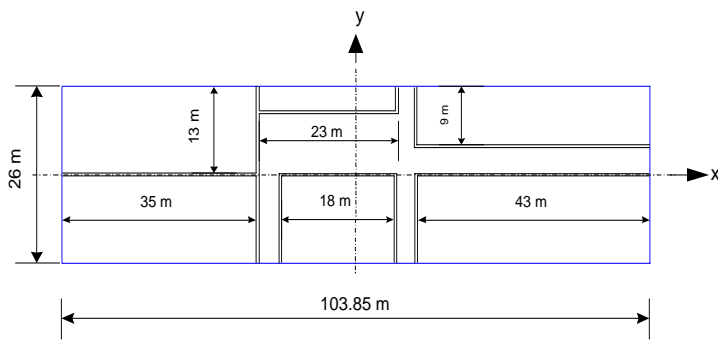

Plan view 1:4 configuration

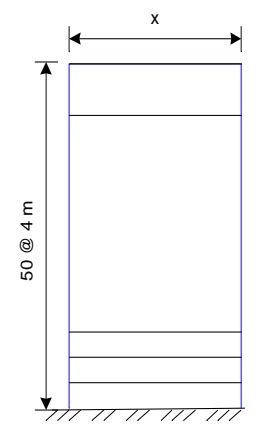

Elevation

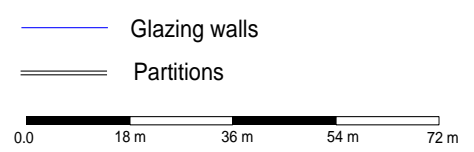

Figure 2: building plan view and envelope thermal properties

Proceedings of First Conference for Engineering Sciences and Technology (CEST-2018), vol. 2 
Built to Code Building Envelop Versus Sustainability of High-Rise Building Performance

\section{Thermal analysis}

Autodesk's Ecotect energy simulation package was used for the thermal analysis. The thermal analysis involves examining each of the four models (1:1,1:2, 1:3, and 1:4) in each of the four climatic zones (cool, temperate, arid, and tropical). That is, the only difference among the four runs for the same climate zone are the building width to length ratio (aspect ratio) for one orientation at a time. Ecotect calculates the overall heat gain/loss (Sun-path diagram Figure 3); and then with choose the way the comfort zones is calculated of each day of the year using the Flat Comfort Bands method, which sets upper and lower limits for comfort temperatures. If the internal zone temperature is either above or below the temperature limits for the prescribed comfort zone, then thermal environmental conditions are unacceptable to the majority of the occupants within that space. Factors that determine thermal environmental conditions are temperature, thermal radiation, humidity, air speed, and personal factors such as activity and clothing. Environmental factors are influenced by: (1) Direct solar gain, or radiant flow through transparent surfaces. (2) Internal (sensible) heat gain from lights, people, and equipment. (3) Conductive heat flow through opaque (envelope) elements. (4) Radiant flow through opaque (envelope) elements. (5) Ventilation and infiltration heat flow through cracks and openings. (6) Inter-zonal heat flow between adjacent zones, which for this analysis is negligible. Conductive and radiant flows through opaque elements are treated together and described as "Fabric" in Ecotect. Personal factors such as activity (metabolic rate) and clothing (insulation of clothing) are treated as constant for all building occupants.

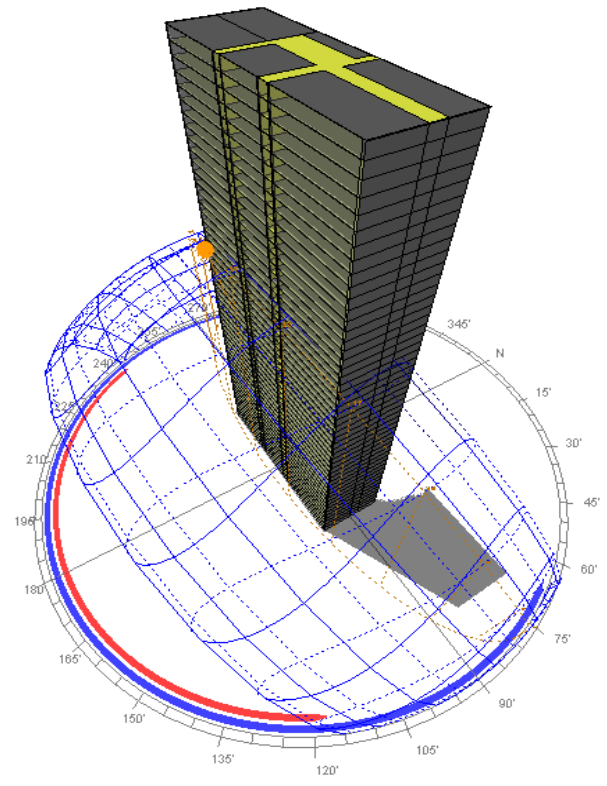

Figure 3: Sun-Path Diagram 
Mohamed ali karim., CEST-2018, AIJR Proceedings 4, pp.369-378, 2018

In this study, there are two main steps of the thermal analysis. The first step is to find the sensitivity of the energy demand (heating and cooling loads) to the change of the surface area ratio (SAR), which relates to floor-plan aspect ratio:

$S A R=\frac{(\text { floor perimeter } \times \text { floor height })}{\text { floor plan area }}$

This analysis consists of thirty-two different simulation runs (of four models in two orientations in four climate zones), where annual cool and heating loads are calculated for each model. The results corresponding to the N-S orientation are provided in Table 1; and the difference in total energy demands between the N-S and E-W orientations is not significant.

Table 1: Energy demand verses SAR (N-S orientation)

\begin{tabular}{|c|c|c|c|c|c|c|c|c|c|c|c|c|}
\hline \multicolumn{13}{|c|}{ Width to length ratio - increase in SAR } \\
\hline \multirow{3}{*}{$\begin{array}{l}\text { : } \\
\text { : }\end{array}$} & \multicolumn{3}{|c|}{ 1:1 } & \multicolumn{3}{|c|}{$1: 2$} & \multicolumn{3}{|c|}{$1: 3$} & \multicolumn{3}{|c|}{$1: 4$} \\
\hline & Heating & Coolin & EUI & Heating & Cooling & EUI & Heating & Cooling & EUI & Heating & Cooling & EUI \\
\hline & \multicolumn{3}{|c|}{$\mathrm{kwh} / \mathrm{m}^{2}$} & \multicolumn{3}{|c|}{$\mathrm{kwh} / \mathrm{m}^{2}$} & \multicolumn{3}{|c|}{$\mathrm{kwh} / \mathrm{m} 2$} & \multicolumn{3}{|c|}{$\mathrm{kwh} / \mathrm{m} 2$} \\
\hline$\overline{8}$ & 49.8 & 9.4 & 59.2 & 51.9 & 9 & 60.9 & 53.6 & 8.7 & 62.3 & 55.9 & 8.4 & 64.3 \\
\hline 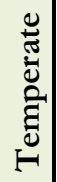 & 7.9 & 30.7 & 38.5 & 8.4 & 30.7 & 39.1 & 8.9 & 30.8 & 39.8 & 9.7 & 31 & 40.6 \\
\hline$\frac{\pi}{4}$ & 5.8 & 57 & 62.8 & 6.1 & 57.9 & 64.0 & 6.5 & 59 & 65.5 & 7 & 60.4 & 67.4 \\
\hline 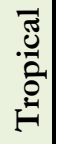 & 0.0 & 62.5 & 62.5 & 0.0 & 62.75 & 62.6 & 0.0 & 63.4 & 63.4 & 0.0 & 64.1 & 64.1 \\
\hline
\end{tabular}

Via the model of 1:4 aspect ratio as an example, the monthly and yearly energy demand ratios (EDR) for each of the four climate zones are shown in Table 2.

$$
E D R=\frac{\text { energy demand of East }- \text { West orientation }}{\text { energy demand of } \text { North }- \text { South orientation }}
$$


Built to Code Building Envelop Versus Sustainability of High-Rise Building Performance

In addition, the passive solar heat gains ratio (PSHGR) of the model of 1:4 aspect ratio displayed in Figure 4. Moreover, the total heat gain and heat to gain ratio (HGR) of the month of July are broken down into individual sources of direct (solar) gain, internal gain, fabric, and ventilation.

Table 2: Energy demand ratio, EDR, (model of 1:4 aspect ratio)

\begin{tabular}{|c|c|c|c|c|}
\hline \multirow{2}{*}{ Months } & \multicolumn{4}{|c|}{ Energy demand ratio (EDR) } \\
\cline { 2 - 5 } & Cool & Template & Arid & Tropical \\
\hline Jan & 1.01 & 1.01 & 1.03 & 0.96 \\
\hline Feb & 1.01 & 1.02 & 0.97 & 0.99 \\
\hline Mar & 1.01 & 0.99 & 0.99 & 1.05 \\
\hline Apr & 0.99 & 1.02 & 1.04 & 1.07 \\
\hline May & 0.97 & 1.04 & 1.05 & 1.06 \\
\hline Jun & 0.99 & 1.04 & 1.03 & 1.05 \\
\hline Jul & $\mathbf{1 . 0 1 1}$ & $\mathbf{1 . 0 3 4}$ & $\mathbf{1 . 0 2 6}$ & $\mathbf{1 . 0 5 5}$ \\
\hline Aug & 1.02 & 1.02 & 1.02 & 1.05 \\
\hline Sep & 1.00 & 0.99 & 1.01 & 1.03 \\
\hline Oct & 1.01 & 0.98 & 0.99 & 1.01 \\
\hline Nov & 1.02 & 1.00 & 0.99 & 0.99 \\
\hline Dec & 1.02 & 1.02 & 1.03 & 0.97 \\
\hline yearly & $\mathbf{1 . 0 1}$ & $\mathbf{1 . 0 2}$ & $\mathbf{1 . 0 2}$ & $\mathbf{1 . 0 3}$ \\
\hline
\end{tabular}

Table 3, presents the percentage of each of these heat sources and how they vary by orientation. The total energy demand for each orientation is not significantly different, even though the E-W oriented models has a much higher potential for passive solar heat gain

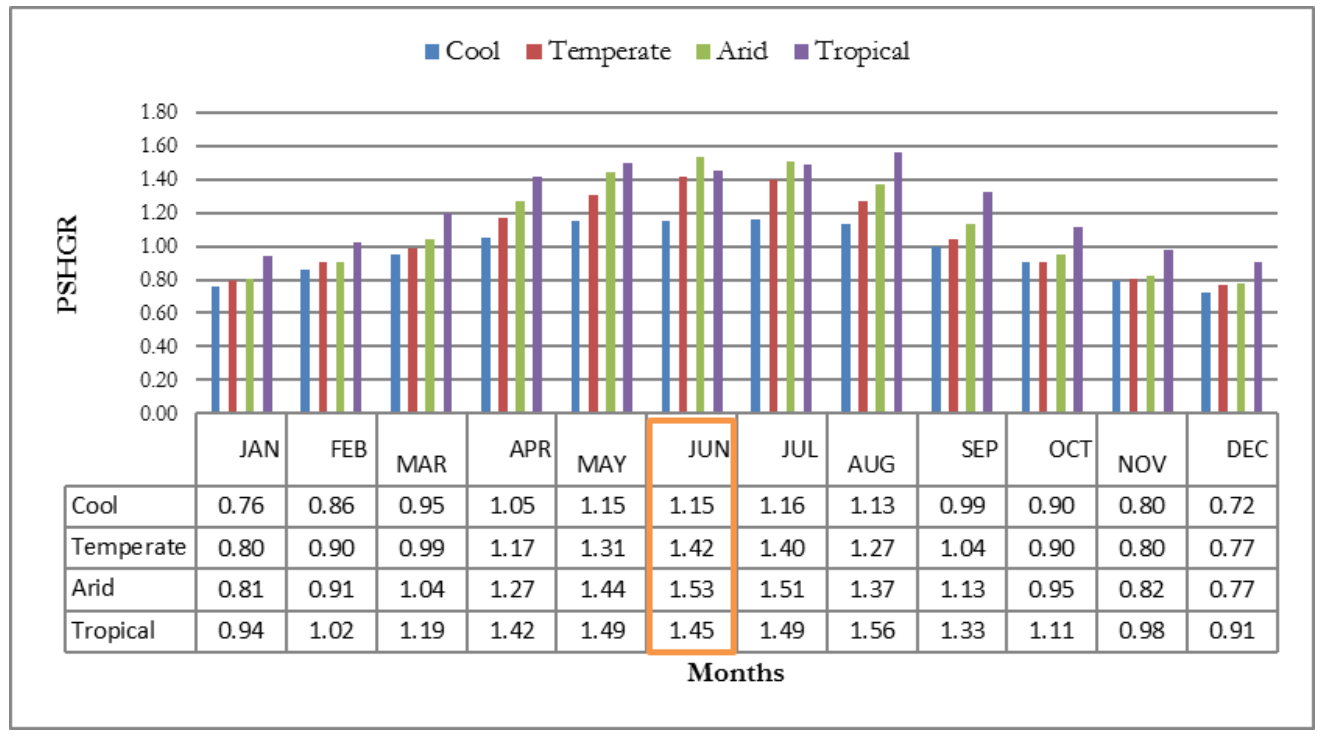

Figure 4: Monthly passive solar heat gain ratio (model of 1:4 aspect ratio) 
Mohamed ali karim., CEST-2018, AIJR Proceedings 4, pp.369-378, 2018

The next stage of the thermal analysis investigates why the differences in the energy demand are negligible. One possible reason maybe because of the thermal properties of the IECC 2009 envelope. In the initial analysis, the glazing walls were modeled with U-factors and SHGC set according to the regional climate. These walls were subsequently modeled using single-pane glazing, which has inferior thermal properties $\left(\mathrm{U}=6.0 \mathrm{~W} / \mathrm{m}^{2} \mathrm{~K} \&\right.$ SHGC=0.94). The simulation was run again to evaluate the total energy demand for each of the two orientations. The results of the new simulation runs show that buildings oriented E-W require $12 \%$ more energy than those oriented N-S, and that the passive solar heat gain in July is significantly increased.

Table 3: Sources of heat gain (Wh) in July- built to code envelope (model of 1:4 aspect ratio)

\begin{tabular}{|c|c|c|c|c|c|c|c|c|c|c|}
\hline Climate & \multicolumn{5}{|c|}{ Cool } & \multicolumn{5}{|c|}{ Temperate } \\
\hline 莡 & \multicolumn{2}{|c|}{$\theta=0$} & \multicolumn{2}{|c|}{$\theta=90$} & July & \multicolumn{2}{|c|}{$\theta=0$} & \multicolumn{2}{|c|}{$\boldsymbol{\theta}=\mathbf{9 0}$} & \multirow{2}{*}{$\begin{array}{c}\text { July } \\
\text { HGR } \\
1.40\end{array}$} \\
\hline Direct & $1.1 \mathrm{E}+8$ & $17 \%$ & $1.3 \mathrm{E}+8$ & $20 \%$ & 1.16 & $1.1 \mathrm{E}+8$ & $8 \%$ & $1.5 \mathrm{E}+8$ & $11 \%$ & \\
\hline Internal & $5.1 \mathrm{E}+8$ & $78 \%$ & $5.1 \mathrm{E}+8$ & $75 \%$ & 1.00 & $5.1 \mathrm{E}+8$ & $40 \%$ & $5.1 \mathrm{E}+8$ & $38 \%$ & 1.00 \\
\hline Fabric & $2.1 \mathrm{E}+7$ & $3 \%$ & $2.3 \mathrm{E}+7$ & $3 \%$ & 1.11 & $2.8 \mathrm{E}+8$ & $22 \%$ & $2.9 \mathrm{E}+8$ & $22 \%$ & 1.02 \\
\hline Ventilation & $1.3 \mathrm{E}+7$ & $2 \%$ & $1.3 \mathrm{E}+7$ & $2 \%$ & 1.00 & $3.8 \mathrm{E}+8$ & $30 \%$ & $3.8 \mathrm{E}+8$ & $29 \%$ & 1.00 \\
\hline Total & $6.6 \mathrm{E}+8$ & & $6.8 \mathrm{E}+8$ & & 1.032 & $1.3 \mathrm{E}+9$ & & $1.3 \mathrm{E}+9$ & & 1.038 \\
\hline Climate & \multicolumn{5}{|c|}{ Arid } & \multicolumn{5}{|c|}{ Tropical } \\
\hline 苞 & \multicolumn{2}{|c|}{$\theta=0$} & \multicolumn{2}{|c|}{$\theta=90$} & $\begin{array}{c}\text { July } \\
\text { HGR }\end{array}$ & \multicolumn{2}{|c|}{$\theta=0$} & \multicolumn{2}{|c|}{$\theta=90$} & $\begin{array}{c}\text { July } \\
\text { HGR }\end{array}$ \\
\hline Direct & $1.1 \mathrm{E}+8$ & $5 \%$ & $1.6 \mathrm{E}+8$ & $8 \%$ & 1.51 & $9.9 \mathrm{E}+7$ & $10 \%$ & $1.5 \mathrm{E}+8$ & $14 \%$ & 1.49 \\
\hline Internal & $5.1 \mathrm{E}+8$ & $25 \%$ & $5.1 \mathrm{E}+8$ & $24 \%$ & 1.00 & $5.1 \mathrm{E}+8$ & $50 \%$ & $5.1 \mathrm{E}+8$ & $47 \%$ & 1.00 \\
\hline Fabric & $6.1 \mathrm{E}+8$ & $30 \%$ & $6.2 \mathrm{E}+8$ & $29 \%$ & 1.01 & $2.2 \mathrm{E}+8$ & $21 \%$ & $2.3 \mathrm{E}+8$ & $21 \%$ & 1.05 \\
\hline Ventilation & $8.3 \mathrm{E}+8$ & $40 \%$ & $8.3 \mathrm{E}+8$ & $39 \%$ & 1.00 & $2.0 \mathrm{E}+8$ & $19 \%$ & $2.0 \mathrm{E}+8$ & $18 \%$ & 1.00 \\
\hline Total & $2.1 \mathrm{E}+9$ & & $2.1 \mathrm{E}+9$ & & 1.03 & $1.1 \mathrm{E}+9$ & & $1.1 \mathrm{E}+9$ & & 1.057 \\
\hline
\end{tabular}

Proceedings of First Conference for Engineering Sciences and Technology (CEST-2018), vol. 2 376 
Built to Code Building Envelop Versus Sustainability of High-Rise Building Performance

\section{Results:}

\subsection{Demand sensitivity-glazing walls built to code.}

For each building in the climate zones of Cool, Temperate, and Arid, the change in energy demand is slightly significant, where by increasing the surface area (up to $20 \%$ ), energy demand is increased by $5.1-7.9 \%$ (Table 1 ) depending on the climate zone. In the tropical climate, however, the energy demands is insensitive to the variations in SAR, where the average increment percent is $0.4 \%$ and the total increase is $0.84 \%$. Of course, an increase in the surface area (SAR) is likely to lead to an increase in the materials used, may influence construction costs and embodied energy. Furthermore, increases in the surface area may result in an increase in the area exposed to wind pressure, which might lead to the need of a larger size of structural element, which also influence construction costs and embodied energy. The differences in the total energy demand for two building orientations (N-S \& E-W) in each climate zone are nearly negligible. Figure 4, demonstrating monthly breakdown solar heat gains and losses resulting from building oriented E-W are much greater than those if the building was oriented N-S. Table 3, clarifies that the influence of solar loads is small compared to internal, fabric, or ventilation loads. The amount of heat gain from passive sources represents $5-20 \%$ of the total heat gain. This is consistent for both orientations, and the effect is trivial compared to the total heat gain.

\subsection{Demand sensitivity with non-code-compliant glazing on walls}

The second stage of thermal analysis is an investigation of the sensitivity of built- to-code glazing systems on passive solar heat gain, compared to single-pane glazing, which has poorer thermal properties. The outcome demonstrates that code requirements for glazing systems results in reductions in direct heat gain to become to represent $5 \%$ rather than $24 \%$ of total heat gain (N-S), while become to represent $8 \%$ rather than $34 \%$ of total heat gain(E-W), (Table $3 \&$ Table 4 for arid climate). Code-built glazing also reduces total energy demands by $12 \%$, which also explains why there is such a small effect of varying building orientation on monthlies and yearly energy demand.

Table 4: Breakdown heat gain (Wh) in July in Arid climate - regular glass envelope (model of

$1: 4$ aspect ratio)

\begin{tabular}{|c|c|c|c|c|c|}
\hline \multirow{2}{*}{} & \multicolumn{4}{|c|}{ Heat gain (Wh) } & \multirow{2}{*}{ July HGR } \\
\cline { 2 - 5 } & \multicolumn{2}{|c|}{$\boldsymbol{\theta = 0}$} & \multicolumn{2}{c|}{$\boldsymbol{\theta = 9 0}$} & \\
\hline Direct & $7.4 \mathrm{E}+08$ & $24 \%$ & $1.2 \mathrm{E}+09$ & $34 \%$ & 1.62 \\
\hline Internal & $5.1 \mathrm{E}+08$ & $16 \%$ & $5.1 \mathrm{E}+08$ & $14 \%$ & 1.00 \\
\hline Fabric & $1.0 \mathrm{E}+09$ & $33 \%$ & $1.0 \mathrm{E}+09$ & $29 \%$ & 1.01 \\
\hline Ventilation & $8.3 \mathrm{E}+08$ & $27 \%$ & $8.3 \mathrm{E}+08$ & $23 \%$ & 1.00 \\
\hline Total & $3.099 \mathrm{E}+09$ & & $3.564 \mathrm{E}+09$ & & 1.15 \\
\hline
\end{tabular}

ISBN: 978-81-936820-6-7 


\section{Conclusions}

By simulating each building configuration using Autodesk's Ecotect, two major conclusions regarding building energy demand can be drawn: (1) For the buildings in Cool, Arid, and Temperate climate zones, the energy demand may be considered marginally sensitive to changes in surface area ratio (SAR). Increasing the envelope surface area by $20 \%$ leads to energy demand increases of 5.1-7.9\% depending on the climate zone. The energy demand for buildings in the Tropical climate zone is insensitive to variations in SAR. (2) The energy performance of high-rise office buildings is not sensitive to the passive solar gain as long as the exterior envelopes are built to IECC 2009 requirements for thermal performance. Finally, high quality thermal properties of code-built envelope systems offer more flexibility to designers with regard to the building site planning (geometry, layout, and orientation) without creating negative impacts on total energy demand. On the other hand, this limits the possibility of maximizing the advantages of passive heat gain. In addition, because built to code buildings are not significantly sensitive to direct solar gain; it leaves little room for other passive design strategies for energy conservation such as shading devices, landscaping, and thermal mass.

\section{References}

[1] K. Yeang, "The Green Skyscraper," Prestel, Munich, 1999

[2] M. Jenks, R. Burgess, "Sustainable urban forms for developing countries," Spon Press, NY, 2004.

[3] J. Straube, "Green building and sustainability," Building science digest, 5: 24, 2006

[4] WBDG. "Energy Codes and Standards," May, 2011. http://www.wbdg.org

[5] United States Green Building Council, “Green building research,” June 2009. http://www.usgbc.org>

[6] W. Reed, “The Integrative design guide to green building”. Hoboken, N.J, 2009

[7] The U.S. Department of Energy Building Energy Codes Program. International Energy Conservation Code 2009. International code council, INC., 2010

[8] ASHRAE STANDARED. Energy Standard for Buildings Except Low-Rise Residential Buildings. ASHRAE, Atlanta, 2010 